\title{
Improving oxygen electrodes by infiltration and surface decoration
}

Hendriksen, Peter Vang; Khoshkalam, Mohamad; Tong, Xiaofeng; Tripkovic, Dordije; Faghihi-Sani, Mohammad Ali; Chen, Ming

\author{
Published in: \\ ECS Transactions \\ Link to article, DOI: \\ $10.1149 / 09101.1413$ ecst \\ Publication date: \\ 2019 \\ Document Version \\ Peer reviewed version \\ Link back to DTU Orbit
}

Citation (APA):

Hendriksen, P. V., Khoshkalam, M., Tong, X., Tripkovic, D., Faghihi-Sani, M. A., \& Chen, M. (2019). Improving oxygen electrodes by infiltration and surface decoration. ECS Transactions, 91(1), 1413-1424.

https://doi.org/10.1149/09101.1413ecst

\section{General rights}

Copyright and moral rights for the publications made accessible in the public portal are retained by the authors and/or other copyright owners and it is a condition of accessing publications that users recognise and abide by the legal requirements associated with these rights.

- Users may download and print one copy of any publication from the public portal for the purpose of private study or research.

- You may not further distribute the material or use it for any profit-making activity or commercial gain

- You may freely distribute the URL identifying the publication in the public portal 


\title{
Improving oxygen electrodes by infiltration and surface decoration
}

\author{
Peter Vang Hendriksen ${ }^{\mathrm{a}}$, Mohamad Khoshkalam ${ }^{\mathrm{b}}$, Xiaofeng Tong ${ }^{\mathrm{a}}$, Dordije Tripkovic ${ }^{\mathrm{a}}$, \\ and Ming Chen ${ }^{\mathrm{a}}$ \\ ${ }^{a}$ Department of Energy Conversion and Storage, Technical University of Denmark, \\ DK-4000 Roskilde, Denmark \\ b Department of Materials Science and Engineering, Sharif University of Technology, \\ P.O. Box 11365-9466, Tehran, Iran
}

For improving competitiveness of SOEC/SOFC-technology it is desirable to reduce the temperature of operation down towards $500{ }^{\circ} \mathrm{C}-600{ }^{\circ} \mathrm{C}$. This requires improvement of the oxygen electrode such that this does not limit performance. Here, we report results on modifying various back-bone type oxygen electrodes via infiltration of materials targeting a surface decoration with Proxide or $\mathrm{Pr}, \mathrm{Ni}, \mathrm{Cu}$-oxides. Different composite back-bone electrodes (based on micron-sized particles) were investigated; $\mathrm{La}_{0.6} \mathrm{Sr}_{0.4} \mathrm{Co}_{0.2} \mathrm{Fe}_{0.8} \mathrm{O}_{3} / \mathrm{Ce}_{0.9} \mathrm{Gd}_{0.1} \mathrm{O}_{2}$, (LSCF/CGO), $\quad \mathrm{La}_{0.6} \mathrm{Sr}_{0.4} \mathrm{FeO}_{3}$ (LSF), and $\mathrm{LaNi}_{0.6} \mathrm{Fe}_{0.4} \mathrm{O}_{3} / \mathrm{Ce}_{0.9} \mathrm{Gd}_{0.1} \mathrm{O}_{2}$ (LNF/CGO). Marked performance improvements could be achieved with the infiltration, including a reduction by a factor of 3 of the polarization resistance at $600{ }^{\circ} \mathrm{C}$ for both LSF and the LSCF/CGO based state of the art electrodes. In a LNF/CGO composite backbone, infiltration with Pr-nitrate led to marked electrode performance improvement; reaching $0.14 \Omega \mathrm{cm}^{2}$ at $550{ }^{\circ} \mathrm{C}$ and $0.4 \Omega \mathrm{cm}^{2}$ at $500{ }^{\circ} \mathrm{C}$, sufficiently fast not to limit overall cell performance (at $550^{\circ} \mathrm{C}$ ).

\section{Introduction}

For improving cost competitiveness of both SOEC and SOFC technology it is desirable to reduce the temperature of operation preferably down towards $500-600{ }^{\circ} \mathrm{C}$, as this will slow down the rate of various degradation processes and allow use of much cheaper materials for auxiliary components. This temperature range would enable use of conventional low-cost stainless steel materials for the interconnects. Currently both the maximum achievable hydrogen production capacity (equivalently; the current density) and the long-term durability of state of the art SOEC cells is limited by the Ni/YSZ-fuel electrode. The Ni re-distributes during operation and depletes towards the electrolyte [1]. The associated reduction in percolating TPB leads to a significant increase in polarization resistance. The effect depends on the local polarization; the stronger one polarizes the electrode the more significant is the depletion [2]. The rate of the $\mathrm{Ni}$ coarsening and Ni-depletion process will strongly decrease with temperature. Hence, it is desirable to reduce the temperature of operation (that is, if one at the same time can improve fuel electrode performance, such that the benefit of reduced Ni mobility is not off-set by the impact of increased polarization). 
A reduction of the temperature of operation will of course increase the polarization resistance of both electrodes and the charge transport resistance of the electrolyte. Among these three terms, it is the oxygen electrode polarization resistance that is most temperature dependent. Hence, to enable a reduction of the operation temperature to 500 - $600{ }^{\circ} \mathrm{C}$ one needs to develop long-term durable oxygen electrodes with acceptable resistance (less than $\sim 0.1 \Omega \mathrm{cm}^{2}$ ) in this temperature regime (alongside ensuring very thin electrolytes to compensate for decrease in conductivity at lower temperatures).

Today the state of the art electrodes applied by the major industrial stakeholders in the SOFC and SOEC area are perovskite-based (LSM, LSC, LSCF). A favorite material is LSCF6482 ( $\left.\mathrm{La}_{0.6} \mathrm{Sr}_{0.4} \mathrm{Co}_{0.2} \mathrm{Fe}_{0.8} \mathrm{O}_{3}\right)$ due to its good balance between electro-catalytic activity and thermo-mechanical properties, with a TEC matching that of NiO/YSZcomposites (that is the structurally dominating component in "anode supported thin electrolyte cells”). Often the perovskites, also offering the electronic current pathway in the electrode, is mixed with CGO to provide a larger effective TPB and faster ionic transport. Electrodes are typically prepared by conventional ceramic processing techniques (printing, spraying) and mildly sintered - balancing requirements of maintaining a high surface area whilst also ensuring sufficient mechanical adherence. Typically, the conventional manufacturing routes result in microstructures with particles/grains in the micron range.

To improve the oxygen electrode performance one can thus apply materials providing even faster oxygen incorporation and/or attempt to improve the microstructure increasing the surface area for the incorporation. On the materials side; materials like $\mathrm{Pr}_{2} \mathrm{NiO}_{4}$ [3] or PrO-surface modified CGO [4] have been shown to provide fast or even faster oxygen incorporation than the classical fast perovskites like LSC $\left(\mathrm{La}_{1-\mathrm{x}} \mathrm{Sr}_{\mathrm{x}} \mathrm{CoO}_{3}\right)$ and LSCF. Also, increased surface area by post sintering infiltration of electro-catalysts has been widely studied as a route to improve electrode performance [5, 6]. By this approach, the electrocatalyst is introduced in a pre-fired backbone (typically of a good ionic conductor) via infiltration with nitrate solutions containing the cations of the desired electro-catalyst. The nitrates are decomposed at low temperature $300-600{ }^{\circ} \mathrm{C}$ leading to formation of nano-particles of the desired oxide phases covering the backbone and providing a high surface area for the oxygen reduction/evolution process.

We are currently working on improving the oxygen electrode via different infiltration schemes. The work has multiple purposes:

- Can one improve state of the art electrodes, e.g. LSCF/CGO composites, merely by introducing Pr-oxide in the structure via infiltration? This approach would hold some merit compared to a completely new electrode structure as the manufacturing route and thermo-mechanical reliability of the host-electrode is well established.

- Can the performance improvement achievable via infiltration be so substantial, that it becomes possible to avoid the use of Co in the oxygen electrode? - i.e. base the electrodes on cheaper material like LSF, LSM or LNF. Co is price-volatile and its handling during manufacturing requires certain health and safety measures further increasing manufacturing costs.

- Some stability issues were observed with highly performing infiltrated electrodes e.g. LSC coated CGO [5] - can one improve durability by performing the surface 
modification in a composite backbone including both CGO and an electronic conductor?

- Can we rationalize the improvement in terms of altered surface area or surface chemistry? To elucidate this we compare investigations on symmetrical cells with composite nanostructured electrodes with investigations of surface exchange kinetics on dense bars of the host material with or without surface decoration with the same compounds used in the infiltration.

Here, we report some preliminary results on above outlined endeavor [7]. Several different composite back-bone electrodes (based on micron-sized particles) were considered including; $\left(\mathrm{La}_{0.6} \mathrm{Sr}_{0.4}\right)_{0.99} \mathrm{FeO}_{3}, \quad \mathrm{LaNi}_{0.6} \mathrm{Fe}_{0.4} \mathrm{O}_{3} / \mathrm{Ce}_{0.9} \mathrm{Gd}_{0.1} \mathrm{O}_{2}$ and $\left(\mathrm{La}_{0.6} \mathrm{Sr}_{0.4}\right)_{0.99} \mathrm{Co}_{0.2} \mathrm{Fe}_{0.8} \mathrm{O}_{3-\delta} / \mathrm{Ce}_{0.9} \mathrm{Gd}_{0.1} \mathrm{O}_{2}$. The backbone electrodes were prepared on both surfaces of a thin CGO $\left(\mathrm{Ce}_{0.9} \mathrm{Gd}_{0.1} \mathrm{O}_{2}\right)$ electrolyte sheet and electrode performance was investigated by impedance spectroscopy. Nitrate precursors were used for the infiltration targeting several different compositions belonging to the material class; $\operatorname{Pr}_{2}\left(\mathrm{Ni}_{1-\mathrm{x}} \mathrm{Cu}_{\mathrm{x}}\right) \mathrm{O}_{4}$ or simply the "end-member" of Pr-oxide $\left(\operatorname{Pr}_{6} \mathrm{O}_{11}\right)$. The rationale for introducing $\mathrm{Cu}$ in the mix targeting a $\mathrm{Pr}_{2} \mathrm{NiO}_{4}$ type material is that we find that it facilitates the formation of the RP-phase and has been reported to improve ionic conductivity [ 8 ]. Furthermore, compositions such as $\operatorname{Pr}_{2} \mathrm{Ni}_{0.8} \mathrm{Cu}_{0.2} \mathrm{O}_{4+\delta}$ and $\mathrm{Pr}_{2} \mathrm{Ni}_{0.75} \mathrm{Cu}_{0.25} \mathrm{O}_{4+\delta}$ shown higher oxygen permeation rates at $1000{ }^{\circ} \mathrm{C}$ than $\operatorname{Pr}_{2} \mathrm{NiO}_{4+\delta}$, which has also been rationalized by density functional theory studies $[9,10]$

The origin of the performance improvement is elucidated by comparing the behavior of the nano-structured infiltrated porous electrodes with simplified model systems. In these, the oxygen exchange is studied on a "decorated" surface, where nano-particles targeting the same composition as in the infiltrated electrodes have been deposited on the surface of a macroscopic bar of the electrode material.

\section{Experimental}

\section{Sample preparation}

To fabricate symmetrical cells, a 50/50wt\% mixture of $\left(\mathrm{La}_{0.6} \mathrm{Sr}_{0.4}\right)_{0.99} \mathrm{Co}_{0.2} \mathrm{Fe}_{0.8} \mathrm{O}_{3-\delta}$ and $\mathrm{Ce}_{0.9} \mathrm{Gd}_{0.1} \mathrm{O}_{1.95}$ (LSCF/CGO), a 35/65wt\% mixture of $\mathrm{LaNi}_{0.6} \mathrm{Fe}_{0.4} \mathrm{O}_{3}$ and $\mathrm{Ce}_{0.9} \mathrm{Gd}_{0.1} \mathrm{O}_{1.95}(\mathrm{LNF} / \mathrm{CGO})$ as well as $\left(\mathrm{La}_{0.6} \mathrm{Sr}_{0.4}\right)_{0.99} \mathrm{FeO}_{3-\delta}$ (LSF) were screen printed on both sides of dense $4 \times 4 \mathrm{~cm}^{2}$ CGO electrolyte (thickness $\sim 200 \mu \mathrm{m}$ ). Fabricated LSCF/CGO and LNF/CGO cells were sintered at $1000{ }^{\circ} \mathrm{C}$ in air, for 5 and 4 hours, respectively. The LSF cells were sintered at $1050{ }^{\circ} \mathrm{C}$ for 5 hours also in air. The weight fraction of LNF was chosen to achieve percolation in the electronically conducting phase [11]. The backbone thicknesses after firing was between 20 and $25 \mu \mathrm{m}$. Smaller 0.9x0.9 $\mathrm{cm}^{2}$ pieces were cut from the $4 \times 4 \mathrm{~cm}^{2}$ cells by laser cutting for subsequent electrochemical characterization.

Aqueous solutions of $\mathrm{Pr}-$, Ni- and $\mathrm{Cu}$-nitrates $(0.5 \mathrm{M})$ were utilized together with 5 wt\% (metal ion basis) of surfactant (Polyethylene-polypropyleneglycol) for the infiltration. The precursor solutions were infiltrated in the sintered backbones by immersing the symmetrical cells in the solution for several seconds (due to capillary forces the solution penetrates the backbone). Excess solution was removed using tissue and the infiltrated cells were heated at $350{ }^{\circ} \mathrm{C}$ for 30 minutes in order to decompose the desiccated nitrates. This procedure was repeated several times, until infiltrate amount 
reaches around $30 \mathrm{wt} \%, 10 \mathrm{wt} \%$ and $5 \mathrm{wt} \%$ of the sintered LNF-CGO-, LSCF-CGO-, and LSF-backbones, respectively. These infiltrate loadings were chosen based on the results of a preliminary study with varying loading, where no performance improvement was observed after reaching this level. Final calcination of the infiltrated precursors were conducted in air in-situ, inside the electrochemical impedance Spectroscopy (EIS) test rig; 2 hours at 600 or $650{ }^{\circ} \mathrm{C}$ for the cases of Pr- and $\mathrm{Cu}$ - infiltrations and at $900{ }^{\circ} \mathrm{C}$ for the case targeting $\mathrm{Pr}_{2} \mathrm{Ni}_{0.7} \mathrm{Cu}_{0.3} \mathrm{O}_{4}$.

For the conductivity relaxation a dense bar of $\mathrm{LSF} 40\left(\mathrm{La}_{0.6} \mathrm{Sr}_{0.4} \mathrm{FeO}_{3}\right)$ was prepared as described in [12]. The surface of the bar was decorated using the same aqueous nitrate precursors as used for the infiltration. Samples were immersed in the solution several times and in between dried/heat treated at $350{ }^{\circ} \mathrm{C}$, which resulted in surface loading of $\approx 15 \mathrm{mg} / \mathrm{cm}^{2}$.

\section{Characterization}

The microstructure of the samples was characterized using SEM and phases formed evaluated by XRD. Pt paste (64021015 Pt Paste, Ferro GmbH, Germany) was hand painted on both sides of symmetrical cells for current collection. Previous studies have demonstrated that thus introduced platinum layers do not have any significant contribution on the electrochemical reactions of the high surface area porous oxygen electrode [13]. Symmetrical cells were sandwiched between two gold grids, which were loaded by a small weight to create the contact needed for the electrical measurements. Details of the EIS test rig and measurement setup can be found elsewhere [5]. EIS measurements were conducted by a Solartron 1260 impedance analyzer using a frequency range of $0.06 \mathrm{~Hz}$ to $1 \mathrm{MHz}$. The measurements were carried out in air under open circuit condition with an AC amplitude signal of $50 \mathrm{mV}$. The impedances were normalized with geometrical area of the electrodes and divided by two, to account for the two electrodes in the symmetrical cell configuration. Series resistance $\left(R_{s}\right)$ as well as $R_{p}$ were determined by measuring the high frequency intercept and difference between the low and high frequency intercepts of real impedance in the Nyquist plane, respectively.

The conductivity relaxation experiments were carried out as outlined in Ref [12]. The bar-shaped sample was heated to $900{ }^{\circ} \mathrm{C}$, and held there for 2 hours, and then cooled stepwise in steps of $50{ }^{\circ} \mathrm{C}$. After the oxygen content had equilibrated at each temperature (conductivity is constant), a change in $\mathrm{pO}_{2}$ around the sample (from 0.2 to $0.1 \mathrm{~atm}$.) was inflicted and the conductivity-changes measured over time. From the response $\mathrm{k}_{\mathrm{chem}}$ and $\mathrm{D}_{\text {chem }}$ was deduced by curve fitting [12]. After determining the temperature dependence of $\mathrm{k}_{\text {chem }}$ the sample was brought to $1000{ }^{\circ} \mathrm{C}$ for 2 hours (re-activation [12]). Hereafter, it was cooled to $650{ }^{\circ} \mathrm{C}$ and the changes in $\mathrm{k}_{\text {chem }}$ were tracked over 10 days by conducting a new set of relaxation experiments (stepping between 0.2 atm. and 0.1 and back) twice per day.

\section{Results and Discussion}

\section{Microstructure}

An example of the electrode structures prior to, and after, infiltration is reproduced in Fig. 1. The characteristic length scale of the highly porous electrode backbone structure is on the order of $0.5 \mu \mathrm{m}$ and grain shapes appear rounded reflecting the electrode firing/sintering temperature. After multiple infiltrations and a heat treatment at $600{ }^{\circ} \mathrm{C}$, a 
much rougher fractal structure is observed as a consequence of formation of a nanostructured surface layer on the electrode backbone.
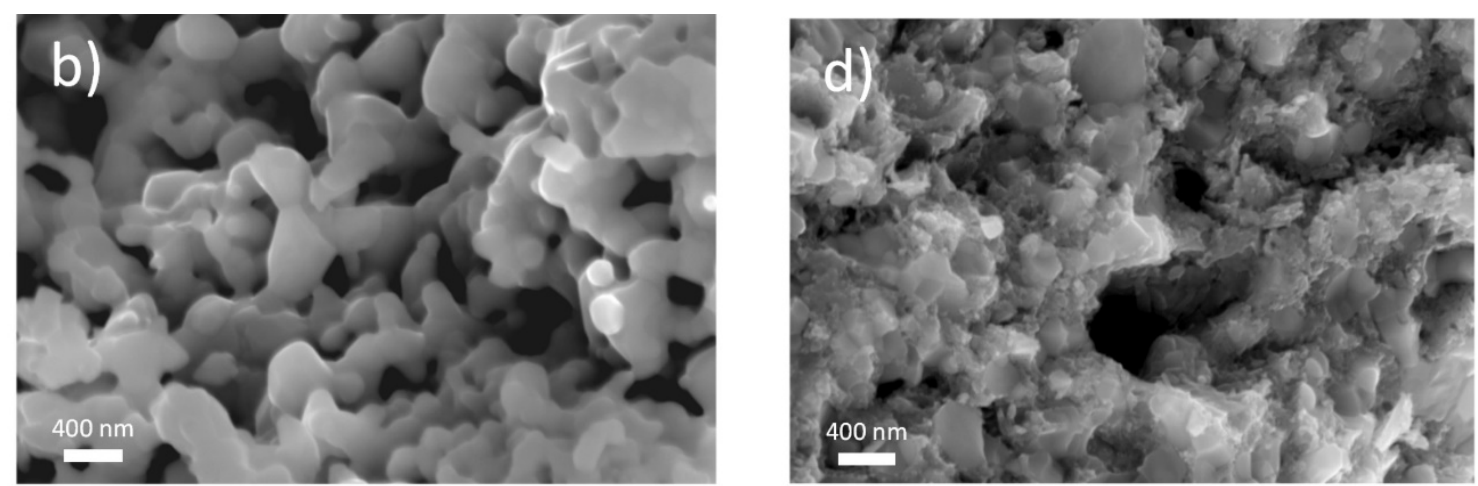

Figure 1. Examples of microstructures (SEM of fractured surfaces) of the backbone before (left) and after infiltration (right). The depicted samples are LNF/CGO-composites before (left) and after Pr-infiltration (right). Maximum temperature of the infiltrated sample was $600^{\circ} \mathrm{C}$.

\section{Electrical characterization by impedance spectroscopy}

Examples of impedance data obtained on the symmetrical cells are reproduced in Figure 2. The data are for an LNF/CGO backbone infiltrated with Cu-nitrates or Pr-nitrates. Evidently the electrode performance is improved with the infiltration both for the $\mathrm{Cu}$ and Pr infiltration; most strongly so for the Pr-nitrates. For the latter case performance is slightly better if the maximum temperature is $600{ }^{\circ} \mathrm{C}$ rather than $650{ }^{\circ} \mathrm{C}$, which could be indicative of a slight coarsening of the nano-particles.

e)

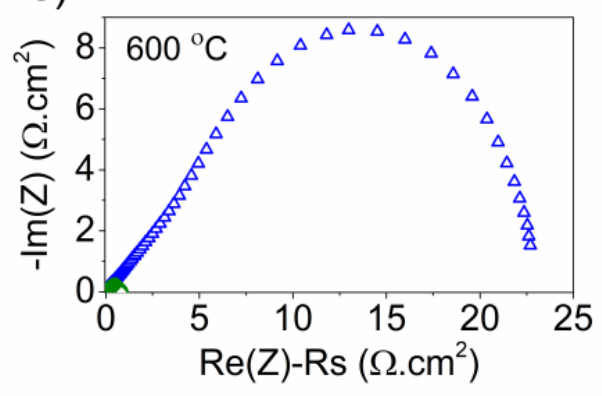

f)

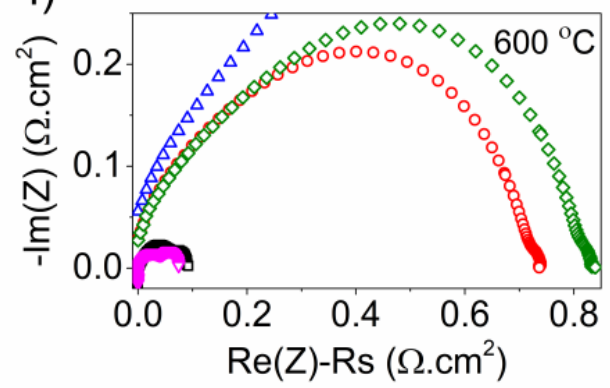

Figure 2. Examples of Nyquist plots of the impedance measured at $600{ }^{\circ} \mathrm{C}$ for the symmetrical cells with LNF/CGO composite electrodes (left) and at the right hand side of similar samples after infiltration with a number of electro-catalyst precursors; Green; $\mathrm{Cu}$ ( $\left.\mathrm{T}_{\max } 600^{\circ} \mathrm{C}\right)$, Red; $\mathrm{Cu}\left(\mathrm{T}_{\max } 650^{\circ} \mathrm{C}\right)$, black; $\operatorname{Pr}\left(\mathrm{T}_{\max } 650^{\circ} \mathrm{C}\right)$, Purple; $\operatorname{Pr}\left(\mathrm{T}_{\max } 600{ }^{\circ} \mathrm{C}\right)$.

\section{Electrode polarization and temperature dependence (overview)}

As outlined in the experimental section several different backbone electrodes and infiltrations were applied. In all cases, the back-bone electrodes were characterized also in absence of infiltration. The performance was evaluated by EIS at different temperatures, and the polarization resistance, and its temperature dependence determined. Results are summarized in Table 1, below. The table also includes results from literature on very well performing electrodes of related compositions. 


\begin{tabular}{|c|c|c|c|c|c|c|c|}
\hline Sample & $\begin{array}{c}\text { Rp } \\
700{ }^{\circ} \mathrm{C} \\
(\Omega . c m 2)\end{array}$ & $\begin{array}{c}\mathbf{R}_{\mathrm{p}} \text { at } \\
650^{\circ} \mathrm{C} \\
\left(\Omega . \mathrm{cm}^{2}\right)\end{array}$ & $\begin{array}{c}\mathbf{R}_{\mathrm{p}} \text { at } \\
\mathbf{6 0 0}{ }^{\circ} \mathrm{C} \\
\left(\Omega . \mathrm{cm}^{2}\right)\end{array}$ & $\begin{array}{c}\mathbf{R}_{\mathrm{p}} \text { at } \\
550^{\circ} \mathrm{C} \\
\left(\Omega . \mathrm{cm}^{2}\right)\end{array}$ & $\begin{array}{c}\mathbf{R}_{\mathrm{p}} \text { at } \\
500{ }^{\circ} \mathrm{C} \\
\left(\Omega . \mathrm{cm}^{2}\right)\end{array}$ & $\begin{array}{c}E_{a} \\
(e v)\end{array}$ & Remark \\
\hline $\begin{array}{c}\text { Pr-inf-LNF/CGO- } \\
\text { Max600C }\end{array}$ & & - & 0.074 & 0.146 & 0.41 & 1.00 & Infiltrated \\
\hline $\begin{array}{c}\text { Pr-inf-LNF/CGO- } \\
\text { Max650C }\end{array}$ & & 0.058 & 0.092 & 0.205 & 0.68 & 1.01 & Infiltrated \\
\hline $\begin{array}{c}\text { Pr-inf-LSCF/CGO- } \\
\text { Max600C }\end{array}$ & & - & 0.081 & 0.210 & 0.72 & 1.27 & Infiltrated \\
\hline $\begin{array}{c}\text { Pr-inf-LSCF/CGO- } \\
\text { Max650C }\end{array}$ & & 0.056 & 0.10 & 0.249 & 0.87 & 1.13 & Infiltrated \\
\hline PrNiCu-inf-LSF & 0.11 & 0.16 & 0.46 & & & 1.01 & Inf. $(30 / 70 \mathrm{Cu} / \mathrm{Ni})$ \\
\hline LNF/CGO & & 7.58 & 22.69 & - & - & 1.59 & Non-infiltrated \\
\hline LSCF/CGO & 0.065 & 0.15 & 0.36 & - & - & 1.13 & Non-infiltrated \\
\hline LSF bare & 0.36 & 0.98 & 3.2 & & & 1.55 & Non-infiltrated \\
\hline
\end{tabular}

Literature

$\begin{array}{cccc}\text { LSC40 in CGO } & 0.044^{*} & \sim 0.3 & \text { Ref [5] } \\ \text { Pr-oxide/CGO, } & 0.028 & 0.15 & \text { Ref [4] } \\ \text { LNF contact I. } & & & \\ \text { Pr2NiO4 in CGO } & 0.075 & & \text { Ref [14] }\end{array}$

Table 1. Overview of the results of the impedance characterization. The table states Rp values measured at five different temperatures. First five rows summarize performance of symmetrical cells after infiltration with either Pr-nitrate or Pr-, Ni-, Cu-nitrates (row 5). Performance of non-infiltrated micron-sized conventional electrodes (the backbones that were infiltrated) are summarized in Rows 6-8. Performance of comparable infiltrated electrodes compiled from literature are reproduced in Rows 10-12. *The value is the initially measured, after 200 hours resistance is $\sim 0.06$.

\section{Effects of Pr-infiltration in LSCF/CGO-composite electrodes}

Evidently, from the results summarized in Table 1 (comparing rows 3, 4 and 7) the performance of a state-of-the-art electrode like a LSCF/CGO composite can be markedly improved by post-firing infiltration with aqueous Pr-nitrate solutions. Rp values are reduced by a factor of three at both 650 and $600{ }^{\circ} \mathrm{C}$. At $600{ }^{\circ} \mathrm{C}$ the electrode that has not experienced any higher temperature than this after infiltration performs slightly better (Rp is $\sim 20 \%$ lower) than for the infiltrated electrode heat treated at $650{ }^{\circ} \mathrm{C}$. After the infiltration treatment, the $\mathrm{Rp}$ is on the order of $0.1 \Omega \mathrm{cm}^{2}$. This is low enough for technological use at this temperature as polarization would only be $\sim 100 \mathrm{mV}$ at $1 \mathrm{~A} / \mathrm{cm}^{2}$. Hence, modifying the state of-the-art electrode by this route seems a feasible way of reducing the temperature of operation as generally desired.

In the LSCF/CGO composite one has already a good electro-catalyst in form of the LSCF, but the Pr-oxide may form additional sites for oxygen reduction directly on the CGO. Indeed, C. Niccollet [4] has prepared some very good electrodes based on infiltrating Pr-nitrates in CGO backbones, where there is no electronically conducting second phase in the backbone. $\operatorname{Pr}_{6} \mathrm{O}_{11}$ is a decent conductor and if $\operatorname{Pr}$ diffuses into the surface of the CGO it will also create some P-type conductivity there. 
Effects of Pr-infiltration in LNF/CGO-composite backbones

Also modification of an LNF/CGO backbone with Pr-oxide was conducted. Results are summarized in Table 1, rows 1, 2 for the infiltrated electrodes and row 6 for the untreated composite. LNF and has a very suitable TEC for application as an SOEC electrode and it is a very good electronic conductor, with conductivities exceeding those achievable with LSCF when limiting the Co content from a TEC-matching criterion. Since Ni is much cheaper than Co it has also a cost advantage compared to LSCF. It is therefore a material of interest for SOEC use. However, it has far inferior oxygen exchange properties compared to LSCF as evident comparing the polarization resistances recorded; at $650{ }^{\circ} \mathrm{C}$ the polarization resistance of the LNF/CGO is more than 50 times higher than for LSCF/CGO. After infiltration, however, also the LNF/CGO-based electrodes become well-performing; polarization resistances are much lower than for the LSCF/CGOcomposite and even 10-20 \% lower than found for the infiltrated LSCF/CGO composites. At $600{ }^{\circ} \mathrm{C}$ the resistance is below $0.1 \Omega \mathrm{cm}^{2}$ rendering the electrodes applicable even slightly below $600{ }^{\circ} \mathrm{C}$. The similar performances achieved with both the LNF/CGO and the LSCF/CGO strongly indicates that after infiltration, the oxygen incorporation takes place on the modified CGO surface rather than on the perovskite.

Hence, the infiltrated LNF/CGO seems very promising for further development and use on real technological cells. Though well-performing the electrode resistance is higher than reported by $\mathrm{C}$. Nicollet for a Pr-oxide infiltrated CGO electrode, reporting polarization resistance of $0.03 \Omega \mathrm{cm}^{2}$ at $600{ }^{\circ} \mathrm{C}$. In [4] LNF was used only on top of the CGO backbone for current collection.

\section{Infiltration of $\mathrm{Pr}, \mathrm{Ni}, \mathrm{Cu}$-Nitrates in LSF-backbone electrodes}

LSF is a well conducting perovskite with a TEC closely matched to NiO/YSZ (the structurally dominating component in "anode-supported" cell types). It is a cheaper material than the cobalt-based perovskites and it is chemically more stable. LSF is a good oxide ion conductor at high temperatures but the surface exchange rate for oxygen incorporation falls short of the cobaltites at low temperature [15]. Here, it was also investigated as a potentially cheap and stable backbone material and whose electrochemical performance we sought to improve by synthesizing $\mathrm{Pr}_{2} \mathrm{NiO}_{4}$-type structure on top the backbone. Whereas the oxygen exchange on Ruddlesden-Popper-type Ni-based compounds like $\mathrm{Pr}_{2} \mathrm{NiO}_{4}$, with interstitial oxygen defects, is known to be very fast [3], reported electrode performance of micron-sized composites based on these types of compounds has fallen short of expectations considering the material properties. This is likely due to the anisotropy of the ionic transport in the compound and challenges with sintering optimization [16]. Using it only in nano-particulate form on top a decent conducting material could alleviate this problem and allow the benefit of the good electrocatalytic properties. In the realization attempted here, $\mathrm{Cu}$ was also added as it has been reported to improve performance of the RP-phase [8].

Comparing the performance of the bare material (row 8) with the material after infiltration there is a marked improvement in performance with infiltration reducing the polarization resistance by a factor of $\sim 6$ at both $650{ }^{\circ} \mathrm{C}$ and $600{ }^{\circ} \mathrm{C}$. At $650{ }^{\circ} \mathrm{C}$ the performance equals that of the LSCF/CGO composite $\left(\mathrm{Rp} \sim 0.16 \Omega \mathrm{cm}^{2}\right)$. Since the ionic conductivity of LSF is inferior to both the one in LSCF and CGO, it is quite remarkable that such a fast electrode can be prepared using an LSF backbone. 
Comparison with conductivity relaxation obtained on surface decorated samples

The effects of surface decoration on the oxygen exchange properties was for the LSF case also investigated by conductivity relaxation and determination of $\mathrm{k}_{\mathrm{chem}}$. The surface of a bar of LSF was modified by decomposing Pr-, Ni- and Cu- nitrates on its surface (see experimental). The temperature dependence of the surface exchange rate constant is reproduced in Fig. 3. The data were obtained on cooling after a two hour period at $900{ }^{\circ} \mathrm{C}$. For comparison, also the values measured on a non-modified bar are shown. Here, actually the performance is slightly higher. Noteworthy, the activation energy of the nonmodified and modified sample is the same. Also shown in Figure 3 are the values that are obtained on a re-heating experiment after prolonged equilibration at low temperature (for pure LSF [12]). We have recently reported that the surface of LSF appears to have two different "states" [12]. Starting from a pristine surface (like a fracture surface) even after mild heating Sr diffuses to the surface making this strongly enriched in Sr compared to the nominal composition. Surface enrichment of Sr may impede surface exchange, but it seems that the actual effect depends on the state of Sr (in which phase it exist) on the surface [17]. After equilibrating the surface for several hours at high temperature and characterizing the exchange as a function of temperature whilst stepwise cooling the sample fast kinetics are observed (upper curve in Fig. 3). If the sample is then kept at lower temperature (e.g. $650{ }^{\circ} \mathrm{C}$ ) over 10-14 days the surface slowly passivates and the $\mathrm{k}_{\text {chem }}$ decreases by a factor $\sim 60$. The kinetics of the process is much like a recrystallization process [12] and accompanying the passivation is a change of the environment of the Sr as evidenced by XPS [17]. Re-heating the sample from this passivated state one finds the temperature dependence of the lower curve in Fig. 3. Interestingly, the phenomenon is reversible - and after a period at high temperature, the sample is again in the activated state.

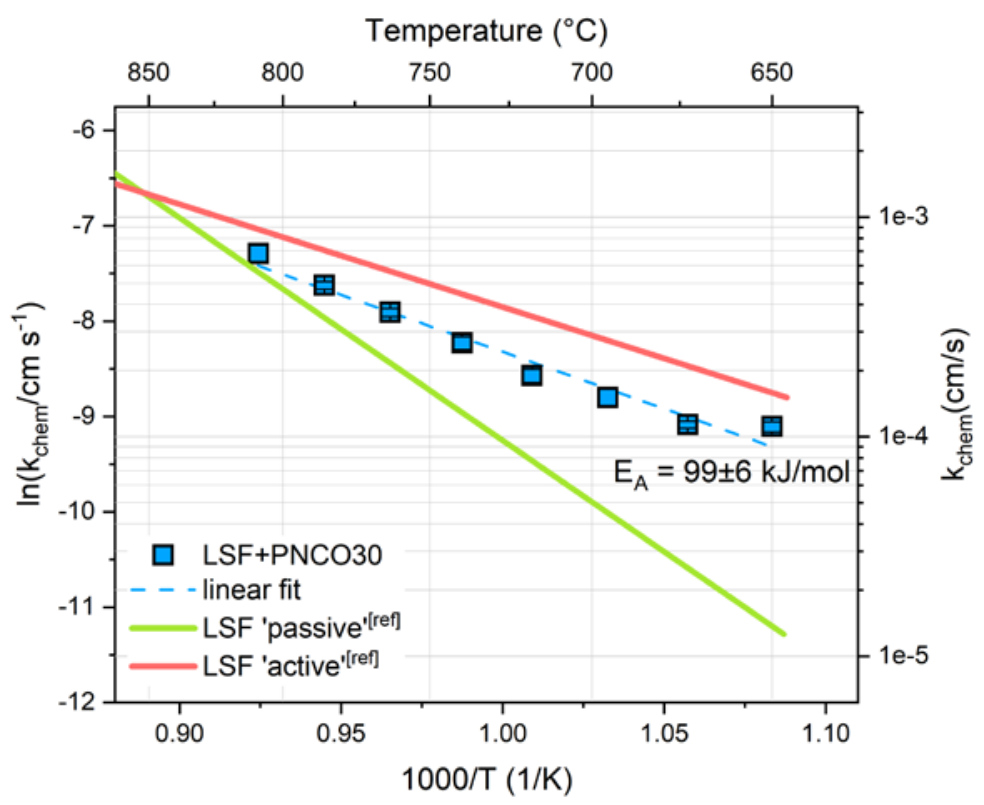

Figure 3. Surface exchange rate constants $\left(\mathrm{k}_{\mathrm{chem}}\right)$ determined on LSF40 bars after applying a $\mathrm{Pr}_{2}(\mathrm{Ni}, \mathrm{Cu}) \mathrm{O}_{4}$ surface decoration (target composition; $\mathrm{Pr}_{2} \mathrm{Ni}_{0.7} \mathrm{Cu}_{0.3} \mathrm{O}_{4}$ ). The two solid lines indicate values measured on bare LSF in "active" or "passivated" sate. The former are the values obtained on cooling after a period at $1000{ }^{\circ} \mathrm{C}$, just after oxygen content has equilibrated, whereas the data for the passivated state are when using low temperature values obtained after several days/weeks at low temperature [12] 
Though the surface modification with $\mathrm{Pr}$-, $\mathrm{Ni}$ - and $\mathrm{Cu}$ does not provide any direct benefit on $\mathrm{k}_{\text {chem }}$ on the LSF surface, rather the value is slightly reduced, it impacts the passivation rate at low temperature. This is illustrated in Fig. 4, showing the $\mathrm{k}_{\mathrm{chem}}$ measured at $650{ }^{\circ} \mathrm{C}$ over 10 days. Evidently, the unmodified LSF surface passivates much faster than the decorated one. Hence, even if the surface-decoration here applied does not provide improved incorporation rate on the bar initially, it seems to help to maintain the surface in the active state. This means that after prolonged use at $650{ }^{\circ} \mathrm{C}$ the modified surface is faster (see Fig. 4).

We would expect that the activation/passivation observed on LSF bars (shown to be reproducible and reversible and to be related to the phases in which $\mathrm{Sr}$ is found on the surface) would also manifest themselves when this material is used as a porous backbone electrode. More work is ongoing to relate the surface chemistry and phases present on the surfaces to the measured exchange rates and to try and bridge between observations on bars and in micron-sized composites.

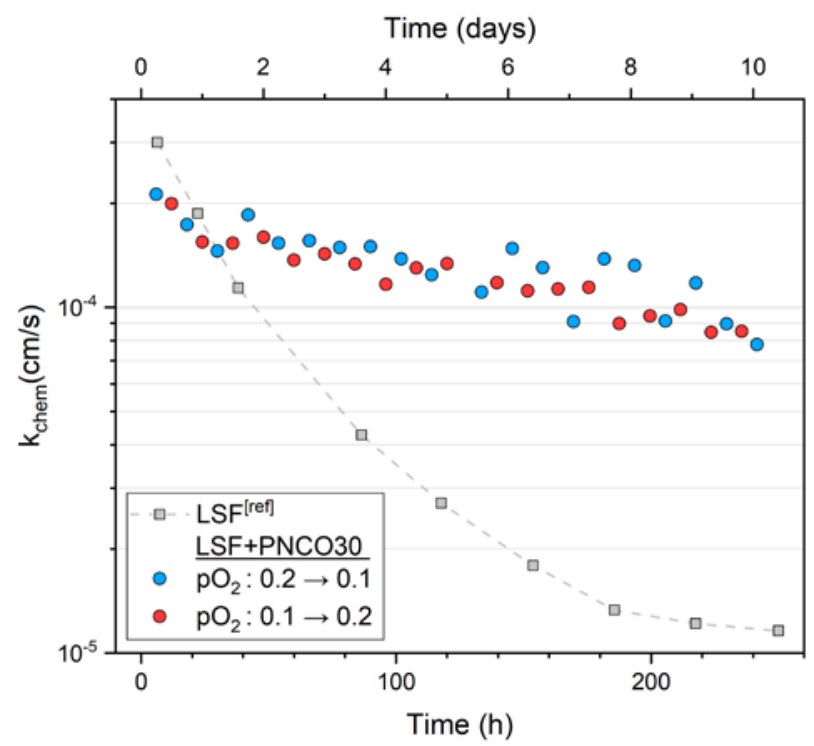

Figure 4. The variation in $\mathrm{k}_{\text {chem }}$ with time at $600{ }^{\circ} \mathrm{C}$ for the $\operatorname{Pr}_{2}(\mathrm{Ni}, \mathrm{Cu}) \mathrm{O}_{4}$ decorated LSF sample. The behavior of a non-surface decorated sample (squares, dashed curve) are shown for comparison.

\section{Stability of the infiltrated electrodes}

The stability of the infiltrated electrodes was also investigated. Results for three of the tested symmetrical cells are reproduced in Fig. 5. The cells were tested in air at $650{ }^{\circ} \mathrm{C}$. The infiltrated electrodes do show fair stability at this temperature, where performance is good enough for technological use (resistance is below $0.1 \Omega \mathrm{cm}^{2}$ ). Although the test period of 200 hours is too short to demonstrate technological feasibility, it is a promising result. The polarization resistance is ca. half the one of the non-modified LSCF/CGO and the degradation rate is smaller than the one observed on the non-modified one. The Proxide decorated LNF/CGO electrode does not degrade over the test period.

At this temperature better performance has been reported for CGO backbones infiltrated with La-Sr-Co-Nitrates. At $600{ }^{\circ} \mathrm{C}$ the Rp of the here developed electrodes are 
ca. twice the value reported by Samson et al. [5]. However, the tentative conclusion is that stability here is better.

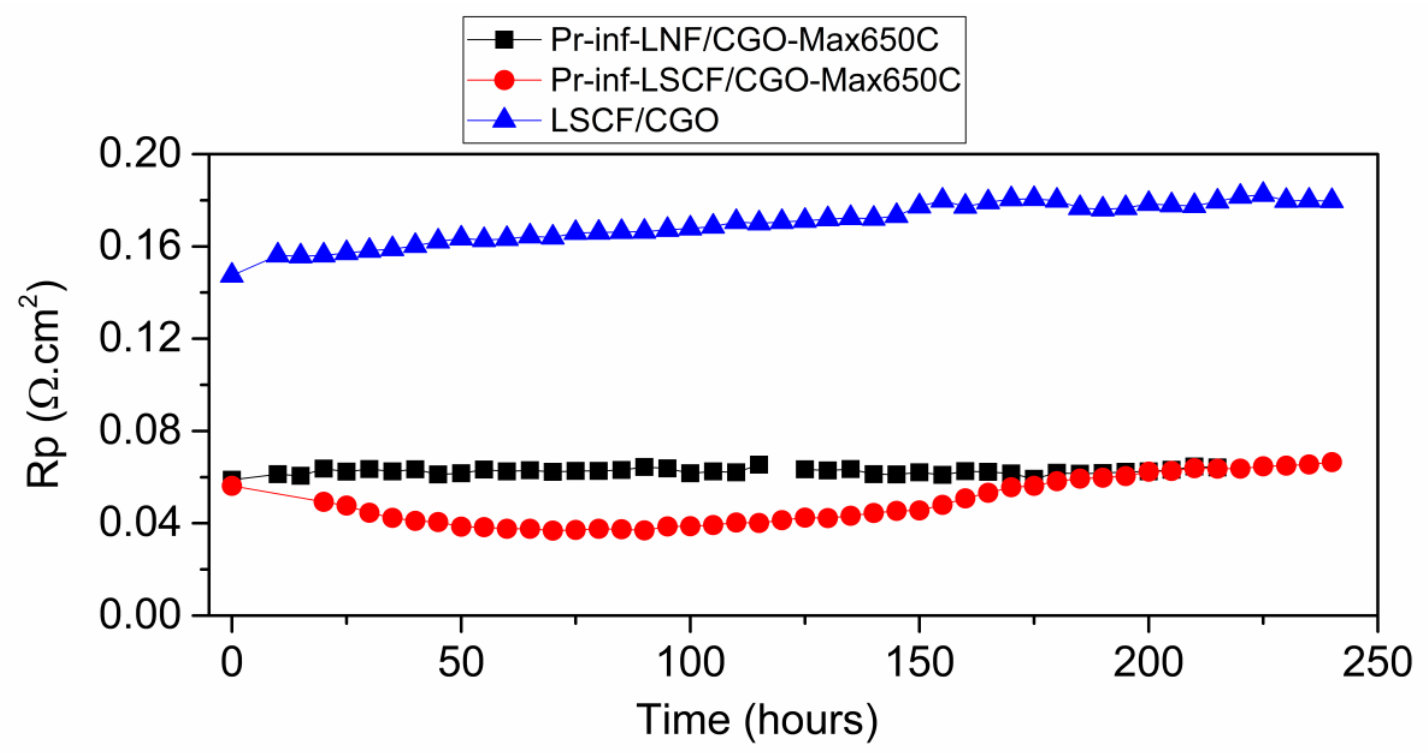

Fig. 5. Variation of $\mathrm{R}_{\mathrm{p}}$ with time at $650{ }^{\circ} \mathrm{C}$ over a 10 day period for the LSCF/CGO composite electrode (blue triangles) and two of the infiltrated electrodes (LNF/CGObackbone, black and LSCF/CGO-backbone; red). Samples were characterized in air.

\section{Conclusions}

Infiltrating aqueous nitrates solutions containing $\mathrm{Pr}, \mathrm{Ni}$ and $\mathrm{Cu}$ can be used to boost performance of composite backbone oxygen electrodes. In summary, it is concluded:

- Good micron-sized LSCF/CGO composite electrodes can be further markedly improved for low temperature operation by repeated Pr-Nitrate infiltrations effectively enhancing the temperature window of operation. The polarization resistance can be reduced by a factor of three at $600{ }^{\circ} \mathrm{C}$.

- Use of nano-particulate Pr-oxide depositions is not only effective in LSCF/CGO composite backbones, but can also be used to boost performance of LNF/CGO composites, that even slightly out-performs the infiltrated LSCF/CGO.

- The long term stability of the surface modified electrodes is not yet proven over technologically relevant time scales, but over the 10 day tested - excellent stability is observed.

- Even with relatively poor low temperature oxide ion conductors like LSF fairly fast electrodes can be prepared with surface modification (targeted composition $\mathrm{Pr}_{2} \mathrm{Ni}_{0.7} \mathrm{Cu}_{0.3} \mathrm{O}_{4}$ ) resulting in $\mathrm{Rp}$ values at $650{ }^{\circ} \mathrm{C}$ of $0.16 \Omega \mathrm{cm}^{2}$ matching that of conventional LSCF/CGO composites.

- The action of surface decoration with RP-like phases on LSF was also investigated by conductivity relaxation experiments, revealing that the passivation occurring at low temperature $\left(600-650{ }^{\circ} \mathrm{C}\right)$ by surface recrystallization on LSF [12] is impeded on the modified surface.

- Surface modification by Pr-containing oxides on perovskite/CGO composite backbone electrodes is an effective route to improve electrode performance. 


\section{Acknowledgments}

The work was in part supported by the project; Synfuel (Innovation fund Denmark 410600006B)

\section{References}

[1] M. Trini, P. S. Jørgensen, A. Hauch, J. J. Bentzen, P. V. Hendriksen, and M. Chen, Journal of The Electrochemical Society, 166 (2) F158-F167 (2019)

[2] M. Trini, A. Hauch, P. Vang Hendriksen, M. Chen, To be submitted in 2019.

[3] J.-M. Bassat, M. Burriel, O. Wahyudi, R. Castaing, M. Ceretti, P. Veber, I. Weill, A. Villesuzanne, J.-C. Grenier, W. Paulus, J. A. Kilner, The Journal of Physical Chemistry C, 117, 26466-26472, (2013).

[4] C. Nicollet, A. Flura, V. Vibhu, A. Rougier, J.M. Bassat, J.C. Grenier, Int. J. Hydrogen Energy 41 (2016) 15538-15544.

[5] A. Samson, M. Søgaard, R. Knibbe, N. Bonanos, J. Electrochem. Soc. 158 (2011) B650-B659

[6] J.M. Vohs, R.J. Gorte, High-performance SOFC cathodes prepared by infiltration, Adv. Mater. 21 (2009) 943-956.

[7] M. Khoshkalam, M.A. Faghihi-Sani, Đ. Tripković, X. Tong, M. Chen, P.V. Hendriksen, On the enhanced electrocatalytic activity of $\operatorname{Pr}_{2} \mathrm{Ni}_{1-\mathrm{x}} \mathrm{Cu}_{\mathrm{x}} \mathrm{O}_{4+\delta}$ infiltrated $\left(\mathrm{La}_{0.6} \mathrm{Sr}_{0.4}\right)_{0.99} \mathrm{FeO}_{3-\delta}$ oxygen electrodes (in preparation).

[8] Junji Hyodo, Ken Tominaga, Young-Wan Ju, Shintaro Ida, Tatsumi Ishihara, Solid State Ionics 256 (2014) 5-10.

[9] S. Miyoshi, T. Furuno, O. Sangoanruang, H. Matsumoto, T. Ishihara, Journal of the Electrochemical Society 154 (2007) B57-B62.

[10] M. Yashima, H. Yamada, S. Nuansaeng, T. Ishihara, Chemistry of Materials, 24 (2012) 4100-4113.

[11] C.H. Kuo, P.K. Gupta, Acta Metall. Mater. 43 (1995) 397-403.

[12] Đ. Tripković, R. Küngas, M. B. Mogensen, P.V. Hendriksen, J. Mater. Chem. A 7 (2019) 11782-11791.

[13] A.J. Samson, "Cathodes for solid oxide fuel cells operating at low temperatures" (Ph.D. Thesis), Technical University of Denmark, 2012.

[14] Nicollet, C., Flura, A., Vibhu, V. et al. J Solid State Electrochem (2016) 20: 2071

[15] M. Søgaard, P. V. Hendriksen and M. Mogensen, Journal of Solid State Chemistry, 180 (4), 1489-1503 (2007).

[16] Y. Chen, W. Zhou, D. Ding, M. Liu, F. Ciucci, M. Tade, Z. Shao, Advanced Energy Materials, 5 (2015) 1500537.

[17] Đorđije Tripković, "Impact of surface chemistry on oxygen exchange in perovskite electrodes”, PhD-Thesis, DTU-Energy, Technical University of Denmark (2018). 